\title{
Evaluating peer-supported screening as a hepatitis C case-finding model in prisoners
}

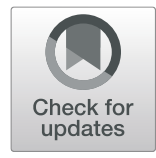

\author{
Desmond Crowley ${ }^{1,2^{*}}$ (D) Ross Murtagh ${ }^{2}$, Walter Cullen ${ }^{2}$, Mary Keevans ${ }^{3}$, Eamon Laird ${ }^{4}$, Tina McHugh ${ }^{5}$, \\ Susan McKiernan ${ }^{6}$, Sarah Jayne Miggin ${ }^{6}$, Eileen O'Connor ${ }^{2,5}$, Deirdre O'Reilly ${ }^{3}$, Graham Betts-Symonds ${ }^{7}$, \\ Ciara Tobin ${ }^{8}$, Marie Claire Van Hout ${ }^{9}$ and John S. Lambert ${ }^{2,5}$
}

\begin{abstract}
Background: Hepatitis C Virus (HCV) infection is endemic in prison populations, and HCV management in prisons is suboptimal. Incarceration is a public health opportunity to target this cohort. Community peer support increases HCV screening and treatment uptake. Prison peer workers have the potential to support the engagement of prisoners with health services and reduce stigma. This study's primary aim is to evaluate peer-supported screening as a model of active HCV case finding with a secondary aim to describe the HCV cascade among those infected including linkage to care and treatment outcomes.

Methods: An observational study was conducted in a medium-security Irish male prison housing 538 inmates, using a risk-based questionnaire, medical records, peer-supported screening, laboratory-based HCV serology tests and mobile elastography.

Results: A prison peer-supported screening initiative engaged large numbers of prisoners in HCV screening $(n=$ 419). The mean age of participants was 32.8 years, $92 \%$ were Irish and $33 \%$ had a history of injecting drug use. Multiple risk factors for HCV acquisition were identified including needle sharing (16\%). On serological testing, 87 (21\%) were HCV Ab +ve and 50 (12\%) were HCV RNA +ve of whom $80 \%$ were fibroscaned (25\% showing evidence of liver disease). Eighty-six percent of those with active infection were linked with HCV care, with 33\% undergoing or completing treatment. There was a high concordance with HCV disclosure at committal and serological testing ( $96 \%$ for HCV Ab +ve and 89\% for HCV Ab-ve).
\end{abstract}

Conclusion: Peer-supported screening is an effective active HCV case-finding model to find and link prisoners with untreated active HCV infection to HCV care.

Keywords: HCV, Hepatitis C virus, Screening, Peer-support, Prison, PWID

\section{Background}

Untreated hepatitis $\mathrm{C}$ viral $(\mathrm{HCV})$ infection poses a major public health problem and is endemic in prison populations globally $[1,2]$. Prisoners have multiple risk factors for $\mathrm{HCV}$ acquisition, the most important being unsafe injecting drug use (IDU), a risk which can exist both in the community and while incarcerated [2-5].

Prison offers an ideal opportunity to target this hard-toreach group with screening and other healthcare interventions [6-8]. The identification, treatment and prevention

\footnotetext{
* Correspondence: doctordes@hotmail.com

${ }^{1}$ Irish College of General Practitioners, Lincoln Place, Dublin 2, Ireland

${ }^{2}$ School of Medicine, University College Dublin, Dublin, Ireland

Full list of author information is available at the end of the article
}

of HCV infection in prison populations is a public health priority [4, 9-11] The WHO and other HCV guidelines recommend universal HCV screening for all prisoners [8, 12-16]. Reviews of HCV screening in prisons globally are rare $[9,17]$, but where available, they show that despite most prisons offering HCV screening, uptake is poor, and standardized protocols for HCV management are the exception $[9,10,17]$. Because most prison sentences are of short duration, $\mathrm{HCV}$ linkage to care poses an additional challenge $[4,18,19]$.

A number of successful strategies have been shown to increase HCV screening uptake in prisoners. These include the introduction of opt-out rather than an opt-in policy for screening, the use of point of care testing (POC)

(c) The Author(s). 2019 Open Access This article is distributed under the terms of the Creative Commons Attribution 4.0 International License (http://creativecommons.org/licenses/by/4.0/), which permits unrestricted use, distribution, and 
and dried blood spot testing (DBS) and the targeted screening of at-risk persons on committal (on entry) [9, $10,17,20-23]$. The uptake of risk-based screening is dependent on prisoners admitting to a history of IDU with its associated stigma, a recognised barrier to both $\mathrm{HCV}$ screening and treatment [24].

Recent guidance from the European Centre for Disease Prevention and Control (ECDC) and the European Centre for Monitoring of Drugs and Drug Addiction (EMCDDA) advises that HCV screening be offered to all prisoners and concludes that providerinitiated screening strategies yield a higher uptake than client-initiated strategies [25]. A 2017 systematic review found that HCV screening at prison entry was associated with higher uptake compared to testing during incarceration or pre-release [10]. This review also reported that the use of peer education had a positive impact on the uptake of HIV screening [26].

Of the 600,000 people incarcerated in European prisons at any given time, 3400 are in Irish prisons [18]. Studies on Irish prisoners report high rates of opiate use (50 \%), IDU (43\%) and HCV infection (13\%) [27, 28]. Recent national $\mathrm{HCV}$ screening guidelines recommend the screening of all prisoners and re-screening annually with targeted screening if an HCV transmission risk is identified [16]. HCV treatment in Irish prisons is provided by specialist services. Ireland, like other developed countries, has a large proportion of undiagnosed and untreated $\mathrm{HCV}$-infected individuals incarcerated in its prisons [16].

The study site is one of three locations where in-reach hepatology services, through specialist nurses, are provided in the IPS. HCV direct-acting antivirals (DAA) have been available in Ireland since 2014, with initial availability restricted on cases clinical need (including for prisoners) for budgetary reasons. These restrictions were lifted in 2018, and now DAA including 8-week pan-genotypic regimens can be prescribed to $\mathrm{HCV}$ infected prisoners.

Community-based $\mathrm{HCV}$ peer workers can increase engagement by people who inject drugs (PWID) with $\mathrm{HCV}$ treatment services and reduce associated stigma $[29,30]$. Peer-based prison workers have the potential to engage prisoners in healthcare and high levels of support among staff and prisoners further underpin the benefits [31-34].

This study reports on the feasibility and impact of a peer-supported HCV screening and linkage-to-care intervention to increase the numbers of $\mathrm{HCV}$ infections detected-in particular new infections, linkage to care, treatment engagement and treatment outcomes in the IPS. While a small number of published studies have reported on the effectiveness of $\mathrm{HCV}$ screening initiatives in prisons [10], this study is unique both nationally and internationally in evaluating a peer-supported $\mathrm{HCV}$ screening initiative.

\section{Methods}

The IPS partnered with the European Commission Third Health Programme funded 'HepCare' Project [35] to enhance screening and primary prevention for populations at risk of $\mathrm{HCV}$ infection and specifically implementing an enhanced HCV screening programme at Mountjoy Prison in Dublin Ireland. Ethical approval was obtained from the Mater Ethics Committee as part of the Seek and Treat component of The European Hep Care Project and supported and endorsed by the IPS's ethics group [36].

\section{Setting}

Mountjoy Prison is a large urban prison which at capacity houses 538 sentenced male prisoners.

\section{Peer workers in Irish prisons}

For many years, the Irish Prison Service (IPS) and Irish Red Cross have trained inmates in all Irish prisons as community-based health volunteers. These prison-based volunteers link with the formal prison health system and act as peer educators to improve prison health and safety. They are volunteers from the prison population on enhance regimes (eligible for defined privileges) and the programme is managed and governed by the Irish Red Cross.

\section{Intervention development}

All Irish Red Cross prisoner volunteers $(n=14)$ were invited to a focus group to discuss their experience of $\mathrm{HCV}$ screening and treatment in prison and to provide input into the design and implementation of this study. A draft design of the proposed intervention was completed and presented to a larger implementation group which included prison healthcare and custodial management, prison officers, nurses and doctors and Irish Red Cross staff overseeing the prison volunteer programme.

A researcher-administered questionnaire was developed and piloted by the research team in conjunction with national experts in the area and prisoner groups. The content of the questionnaire was informed by the research tools used in the two previous prison-based prevalence studies and the European 'HepCare' project data collection tool $[27,28,35]$.

The final intervention design included an awareness and educational session for prison volunteers, educational posters and leaflets as promotional materials, a risk-based questionnaire, provision of HCV screening and result disclosure, referrals for on-site fibroscaning, and linkage to treatment. 


\section{Intervention}

The peer-supported screening took place over three, 2-day periods between March 2017 and August 2017. Throughout the study intervention, peer workers accompanied prisoners to the screening sites and promoted the pilot on the landings. This element of the campaign was considered crucial to the engagement of the prisoners in the process. All prisoners were offered BBV screening, but prisoners considered to have severe mental illness undergoing active treatment and prisoners considered to pose a security risk to the research team were excluded from the study (identified by the local medical team).

All study participants were given a patient information leaflet and asked to sign a consent form. No inducements were offered. Study participants were offered blood-borne virus (BBV) testing. Results were given 4 weeks after screening. Results pertaining to prisoners transferred or released were sent on to their relevant medical practitioners. In-reach fibroscaning was available on-site for those found to have HCV infection on screening. Prisoners with untreated chronic HCV infection who remained incarcerated at the study site were referred to in-reach hepatology services for treatment. All clinical data was transferred onto the patients' electronic medical records.

\section{Data collection}

All prisoners who underwent $\mathrm{HCV}$ screening during the peer-supported screening from March 2017 to August 2017 were eligible for inclusion in the study. Data was not collected for all possible participants since the prison population continually changed over this 6-month period.

Data on variables were collected from two sources: the committal interview and the researcher-completed questionnaire. All prisoners routinely complete a nurse committal interview on the day of incarceration which is stored in the prisoners' medical records in the Prison Health Management System (PHMS). From this medical review, we collected the following variables: age, country of origin, history of drug and alcohol use, presence of visible injecting marks and history of sharing needles.

The questionnaire included questions on age, country of origin, incarceration history, drug use history and HCV risk factors, including history of sharing needles and drugtaking paraphernalia, history of tattooing and the sharing of toothbrushes and razors while incarcerated.

Blood samples were sent to the National Virus Reference Laboratory (NVRL) and tested for HIV, HBV and $\mathrm{HCV}$ antibodies. Reflex RNA and genotype testing were performed on all $\mathrm{HCV} \mathrm{Ab}+$ ve samples. A review of the prisoners' medical notes was conducted on prisoners testing $\mathrm{HCV} \mathrm{Ab}+\mathrm{ve}$ and RNA negative to determine those with SVR post-treatment and those with spontaneous clearance. This information was cross-checked with the prisoner for accuracy. Twelve months' follow-up data on linkage to care and treatment outcomes was collected from the participants' electronic medical records.

\section{Statistical analyses}

All data were anonymised and coded, double-entered and checked. Statistical review of the study was performed by a biomedical statistician (EL), and analysis was conducted using the Statistical Package for Social Sciences (version 23.0; SPSS UK Ltd.; Chersey, UK). Data were assessed for normality and where necessary, data were log-transformed for normalisation purposes. Data within tables are primarily expressed as means (SD) or $n(\%)$.

\section{Results}

\section{Demographics}

A total of 425 male prisoners consented to participate in the study. Study participants had a mean age of 32.8 years and $92 \%$ reported Ireland as their country of origin. The mean age of the first incarceration was 20 years, the mean number of incarcerations was 6 and the mean total time spent incarcerated was 7.7 years. Data from committal interview showed that almost $50 \%$ of participants had a past history of drug use. Of those who answered the questions on drug use in the risk questionnaire, $45 \%$ had a history of heroin use and 33\% a history of IDU. The mean age of first drug use was 15 years and first IDU was 20 years. In terms of risk factors for $\mathrm{HCV}$ acquisition (data collected from risk questionnaires), $34.5 \%$ gave a history of sharing drug taking equipment (paraphernalia), $15.8 \%$ of sharing needles in the community, $17.3 \%$ of having had a prison tattoo and $14.2 \%$ a non-sterile community tattoo. Small numbers reported sharing a razor or toothbrush in a prison setting ( $4.2 \%$ and $0.8 \%$ respectively). A total of $36.3 \%$ reported having a history of methadone treatment, and the mean length of time on treatment was 4.9 years (Table 1 ).

\section{Screening results}

Of the 425 prisoners who consented to participate, 419 had a successful serological HCV result. Eighty-seven (21\%) were $\mathrm{HCV} \mathrm{Ab}+\mathrm{ve}, 4$ (1\%) HIV Ab +ve and 3 (< 1\%) $\mathrm{HBV}$ core $\mathrm{Ab}+\mathrm{ve}$. Of those who tested $\mathrm{HCV} \mathrm{Ab}$ +ve, 37 (43\%) were HCV RNA -ve, of whom 27 (31\%) had self-cleared and $10(27 \%)$ had SVR. The remaining 50 (57\%) showed active HCV infection (HCV RNA +ve) representing $12 \%$ of the entire study population (Fig. 1).

\section{Comparison between self-declared status on committal and serological result on peer-supported screening}

The data on self-declared HCV status on committal (collected from the committal interview on the prisoner's electronic patient record) was grouped into declared $\mathrm{HCV} \mathrm{Ab}$ +ve on committal, declared HCV Ab -ve on committal and status unknown (never tested or status unknown). Of those 
Table 1 Demographics of study participants from Mountjoy Prison (March to August 2017)

\begin{tabular}{|c|c|c|c|}
\hline Variable & Participant numbers & Value $n(\%)$ & Mean (SD) \\
\hline$\overline{A g e^{a, b}}$ & 425 & & $32.8(8.9)$ \\
\hline Age of first incarceration ${ }^{a}$ & 364 & & $20.0(7.1)$ \\
\hline Episodes of incarceration ${ }^{a}$ & 359 & & $5.9(8.3)$ \\
\hline Total time incarcerated (years) ${ }^{a}$ & 361 & & $7.7(6.6)$ \\
\hline Age of first drug use ${ }^{a}$ & 281 & & $15.4(7.7)$ \\
\hline Age of first IV use $\mathrm{e}^{\mathrm{a}}$ & 106 & & $20.1(5.4)$ \\
\hline Previous drug use $\mathrm{b}^{\mathrm{b}}$ & 409 & $199(48.7)$ & \\
\hline Shared needles ${ }^{b}$ & 406 & $26(6.4)$ & \\
\hline \multicolumn{4}{|l|}{ Country of origin $(n=425)^{b}$} \\
\hline Ireland & & $389(91.5)$ & \\
\hline West Europe & & $4(0.9)$ & \\
\hline East Europe & & $22(5.2)$ & \\
\hline Africa & & $10(2.4)$ & \\
\hline \multicolumn{4}{|l|}{ HCV acquisition risk factors } \\
\hline History of heroin use & 355 & $161(45.4)$ & \\
\hline History of IV use & 341 & $111(32.6)$ & \\
\hline Shared needle community & 342 & $54(15.8)$ & \\
\hline Shared equipment & 344 & $120(34.9)$ & \\
\hline Shared razor in prison & 357 & $15(4.2)$ & \\
\hline Shared toothbrush in prison & 358 & $3(0.8)$ & \\
\hline Prison tattoo & 358 & $62(17.3)$ & \\
\hline Unsterile tattoo community & 346 & $49(14.2)$ & \\
\hline \multicolumn{4}{|l|}{ Opioid substitution treatment } \\
\hline Methadone treatment history & 342 & $124(36.3)$ & \\
\hline Length of time on methadone maintenance treatment & 101 & & $4.9(6.6)$ \\
\hline
\end{tabular}

$S D$ standard deviation, $I V$ intravenous, $H C V$ hepatitis $C$ virus

a Values are means $( \pm \mathrm{SD})$ for continuous variables or $n(\%)$ for categorical variables

${ }^{b}$ Data from committal interview

screened, 48 (11\%) self-declared HCV Ab +ve at committal, and on screening serology, 46 of whom were HCV Ab +ve, showing a concordance of $96 \%$. Of the 171 who declared HCV Ab -ve on committal, 19 (4\%) were HCV Ab +ve on serology and eight (2\%) were HCV RNA +ve (active infection). This demonstrates a concordance of $89 \%$. Finally, for those unaware of their status at committal, 22 (11\%) were HCV Ab +ve and 11 (5\%) were HCV RNA + ve. A total of 19 (5\% of the study participants screened) new active cases of HCV infection (HCV RNA +ve) were identified through peer-supported screening.

\section{Linkage, assessment and treatment outcomes}

Of the 50 prisoners with active HCV infection, 40 (80\%) had in-reach elastography performed. Of this cohort, 30 (75\%) had scores $<8.5$, five scores of $8.5>12.5$ (fibrosis) and five scores of $\geq 12.5$ (cirrhosis). The outcomes for linkage to care were grouped into three categories: HIV co-infection who were already linked with specialist hospital services $(n=4)$, linked with in-reach hepatology nurse (either already linked or new referral) $(n=39)$ and not linked with either of these services (due to release or inter-prison transfer) $(n=7)$. Treatment outcomes were reported as of September 2018 (>12 months after the peer-supported screening) and under the following headings: completed treatment with SVR, completed treatment awaiting SVR, undergoing treatment, undergoing assessment for treatment and linked to hospital services or community MMT (the study's ethical approval did not allow for data to be collected on prisoners after release).

For the HIV co-infected group, three had completed treatment (two achieving SVR and one awaiting an SVR result) and one was undergoing assessment for treatment. Of those linked with in-reach hepatology services, nine had completed treatment (eight achieving SVR and one awaiting an SVR result), two are on treatment and six are under assessment for treatment. Eighteen of this group were referred to the hospital (St. James'), the 


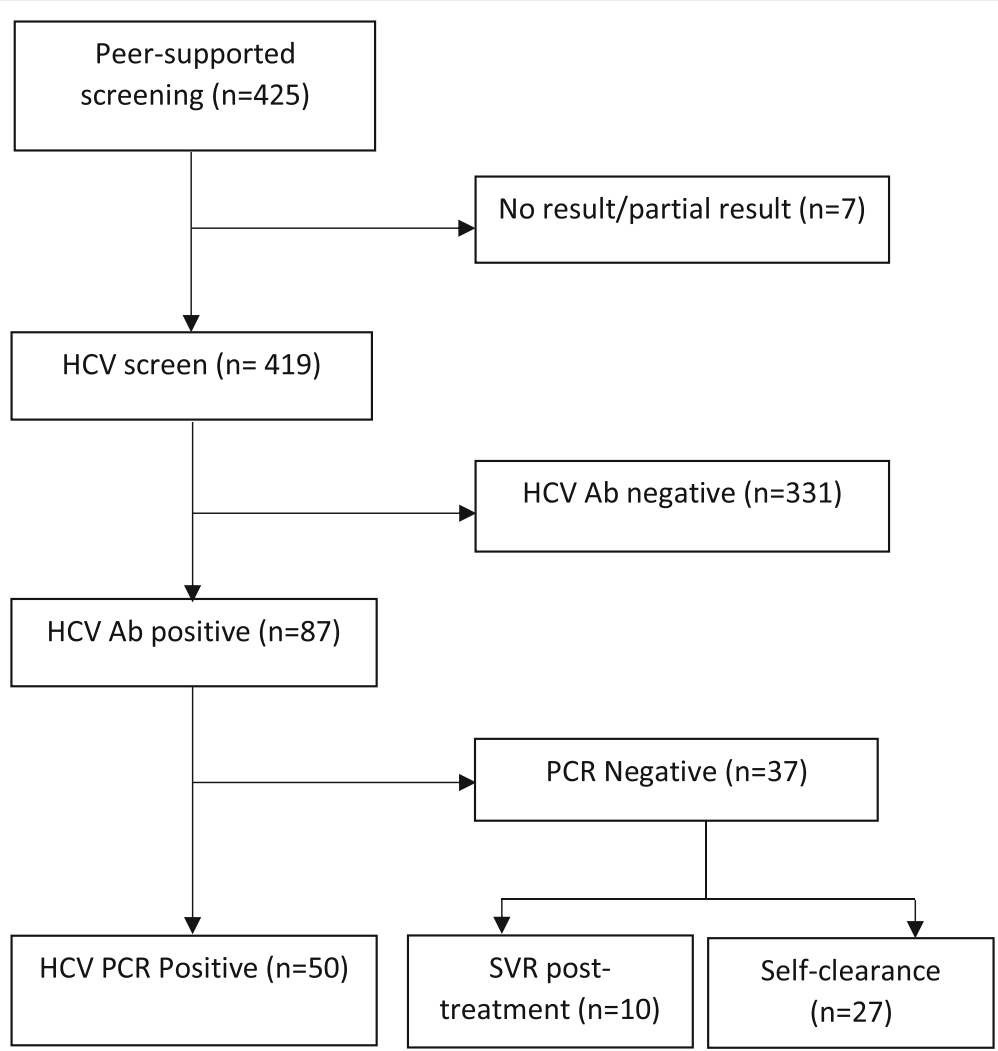

Fig. 1 Peer-supported screening outcomes from Mountjoy Prison, Dublin, Ireland (March 2017 to August 2017)

community location of the specialist hepatology services that provides in-reach to the IPS. Of the final group, five were formally linked to community MMT services and two were lost to follow-up. In summary of the 50 prisoners identified with active $\mathrm{HCV}$ infection, 43 were linked to specialist services and of this group, 12 had completed treatment, 10 achieving SVR, two were under treatment and eight were being assessed. Eighteen of this group had a formal direct referral to the hospital setting providing the in-reach hepatology service (Fig. 2).

\section{Discussion}

This unique Irish prison-based study found that peersupported screening is a feasible active HCV case-finding intervention in a prison setting. It is a convincing example of the benefits of a collaborative prison health intervention using peer-to-peer health promotion and the WHO recommended complete prison approach to planning and implementation [37]. It was successful in testing a large number of prisoners for HCV infection $(n=419)$. It also had the added benefit of testing this cohort for HIV and $\mathrm{HBV}$ infection, BBVs with high prevalence in prison populations [2, 38].

Over half of the study population had a history of drug use, with significant numbers having a history of heroin use and IDU. These figures are similar to other Irish and international studies and reflect the over-representation of PWID in prison populations globally due to the ongoing criminalisation of this underserved and marginalised group [2, 27]. This study also found high levels of self-reported known $\mathrm{HCV}$ risk behaviours in this prison cohort including IDU, sharing needles and other drugtaking paraphernalia and having a prison or non-sterile community tattoo $[2,5,39]$. Peer-supported screening identified 50 cases (12\% of the study population) of active untreated HCV infection of which 19 (5\% of the study population) had not been identified at committal. These findings support the public health focus on prisons as key locations to increase HCV diagnosis, linkage to care and treatment $[4,25,40]$. It also supports the ongoing need to increase harm reduction services (opioid substitution treatment and needle and syringe programmes) within prisons to reduce the risks of BBV transmission in closed settings $[41,42]$.

The use of peer-supported screening as an active $\mathrm{HCV}$ case-finding intervention has not been described previously in the literature [25]. This intervention is a provider rather than client-initiated, a factor which is known to improve uptake [25]. It is an intervention that can be used in prison populations who are already incarcerated and not just for those entering prison. Evidence suggests that screening offered within the first $24 \mathrm{~h}$ of committal has a better uptake 


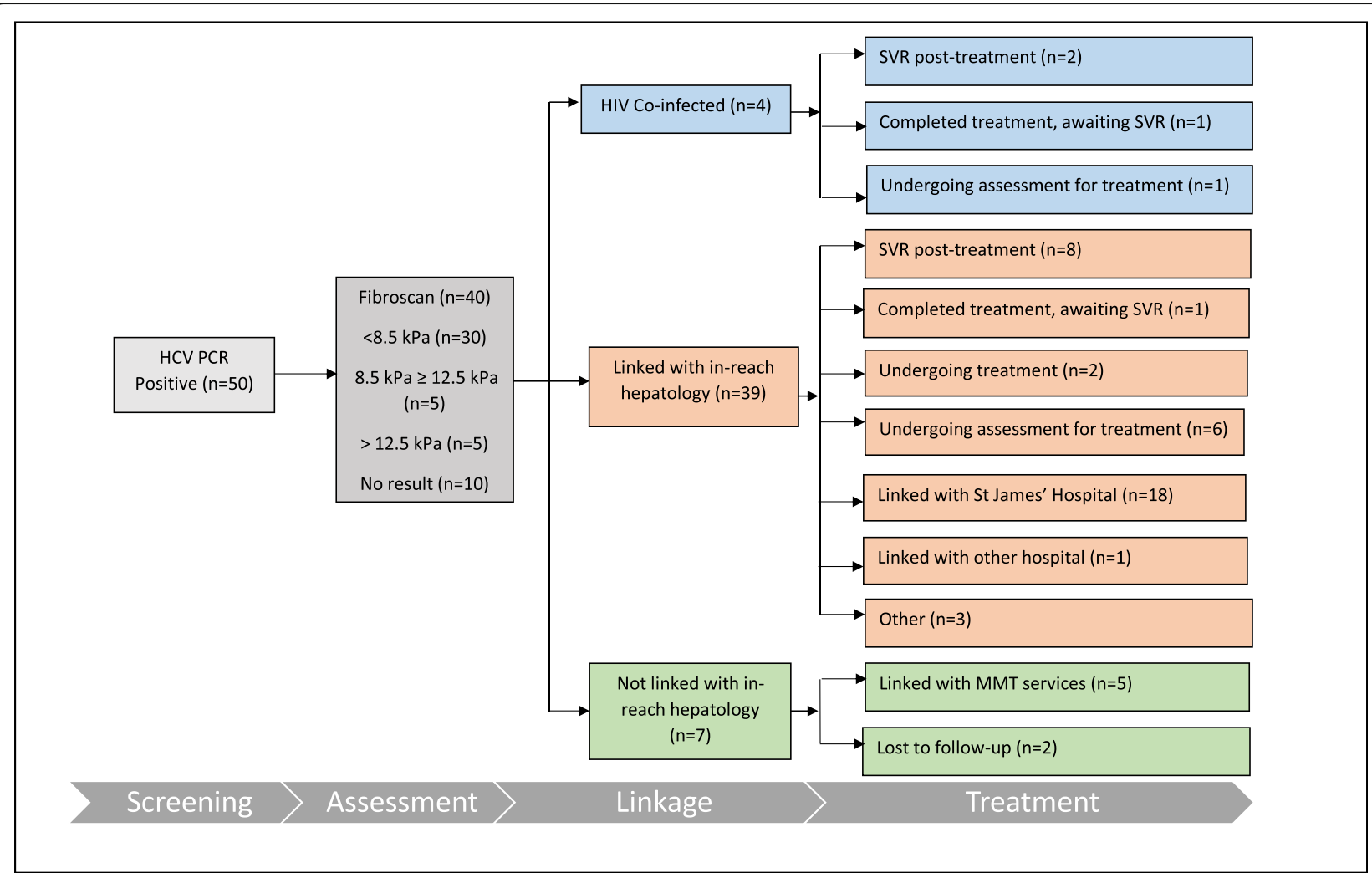

Fig. 2 Peer-supported screening - untreated chronic infection outcomes from Mountjoy Prison, Dublin, Ireland (September 2018). HCV hepatitis C virus, PCR polymerase chain reaction, kPa kilopascal, HIV human immunodeficiency virus, SVR sustained virological response, MMT methadone maintenance treatment

than screening offered later in the custodial sentence or just at pre-release [16, 25]. It is important to remember that efforts to scale up HCV screening and treatment in prisons are a very recent public health intervention and many prisoners globally have been incarcerated since this approach has been more widely adopted. Because of the ongoing risk of $\mathrm{HCV}$ transmission during incarceration, updated international guidelines recommend the repeat screening of all prisoners yearly which will require different strategies than those for screening new entrants to prison $[9,16,25]$. Peersupported screening has the potential to be utilised in these situations.

The use of peers to design, support and implement is intrinsic to this study intervention. Prisoners are identified as a hard-to-reach population, and even in prisons with easier access to healthcare, many still do not engage. There is often a lack of trust between prisoner and staff, and prisoners have identified the fear of stigma as being a key barrier to engagement in the $\mathrm{HCV}$ cascade of care [43-45]. The benefits of peer involvement in community $\mathrm{HCV}$ care are well documented [30, 46-50]. Peer workers can dispel the myths and fears associated with $\mathrm{HCV}$ treatment, reduce stigma, enhance mutual trust, increase social support and increase knowledge and engagement in $\mathrm{HCV}$ care $[30,50]$.

Studies have shown that peer workers have a positive impact on the uptake of $\mathrm{HCV}$ services and have high levels of satisfaction among service users and staff [46, 51]. There is further evidence to suggest that engagement in $\mathrm{HCV}$ care may be facilitated by the influence of peers who completed treatment. The ETHOS study in Australia reported a very strong positive response to peer workers by staff and service users which led to improved access to services, a more client-friendly treatment environment and increased support to services users with assessment and engagement with $\mathrm{HCV}$ treatment [30].

A 2016 systematic review of peer education and support in prison settings found that peer education interventions are effective at reducing risk behaviour, acceptable within the prison environment and have a positive impact on prisoner wellbeing [52]. Peer workers are a credible source of information and have the ability to connect with other prisoners, reduce social stigma and impact positively with a vulnerable patient cohort who is traditionally resistant to professional advice [31]. There are also direct benefits for the peer workers themselves and benefits for the 
wider prison system including more effective use of resources and the ability to expand the range of prison-based health services available to inmates [51]. This study identified peer workers as an enabler to prisoners engaging in $\mathrm{HCV}$ screening and treatment and reducing stigma.

A number of community-based studies have reported on the concordance between perceived HCV status and actual status in PWID [53]. Similar to these studies, this study found high levels of concordance between selfdeclared and serological HCV status. There was a $96 \%$ concordance for those who declared being positive and $89 \%$ for those who declared being negative. These findings are contrary to a 2000 Irish study that found self-declared $\mathrm{HCV}$ status as unreliable with $37 \%$ of those declaring negative being positive on oral swab testing [54]. The difference in findings may be accounted for by the increased numbers attending and the high rates of $\mathrm{HCV}$ testing in community drug treatment services in Ireland. The findings from this evaluation suggest that prisoners can be directed into different care pathways based on self-declared status at committal. This may reduce assessment times and improve linkage to care and treatment outcomes an important consideration in prisons where the majority of prisoners serve short sentences $[18,19]$.

The discordant findings, despite low numbers, are a concern given they represent potential $\mathrm{HCV}$ infection risk and re-enforce the need for regular testing and retesting of prison populations. These findings also highlight the need to improve how we collect HCV data on individuals and populations. $\mathrm{HCV}$-infected people often are unaware of the difference between past infection, chronic infection, active infection, self-clearance, SVR and re-infection. This lack of clarity is also shown in population $\mathrm{HCV}$ surveillance data. Historically $\mathrm{HCV}$ prevalence data in prison populations was reported as $\mathrm{HCV} \mathrm{Ab}+\mathrm{ve}$ prevalence, some more recent studies have reported on HCV RNA +ve prevalence (current active infection) [1, 2, 55]. As we scale up HCV treatment, it is important that serological markers are matched with clinical data so that we can measure levels of active untreated infection, treated infection and re-infections. Furthermore, it is important that HCV-infected persons are educated on the different phases of $\mathrm{HCV}$ infection and their associated blood markers so that they can provide accurate medical information to healthcare staff. Increased accuracy could reduce the need for unnecessary and expensive repeat screening.

This study reports high-levels of linkage to care for prisoners identified as having untreated HCV infection. The presence of the specialist in-reach hepatology nurse facilitated this process with nearly $80 \%$ linked with this service. The use of specialist nurses in prisons has previously been identified as a facilitator to HCV screening and treatment in prison settings $[23,43]$. Treatment outcomes were impacted by a national decision to curtail DAA access to those with advanced liver disease in June 2017. This restriction was lifted in February 2018. The treatment outcomes reported in this study support previously published findings that prisoners (including those infected with HIV) can be successfully treated for HCV with outcomes similar to or better than other population groups $[56,57]$. Many of the HCV-infected participants identified required linkage to hospital-based specialist services on release. This finding underpins the need to support prisoners transitioning back into the community where a range of competing priorities can impact on their ability to link with these services [58, 59]. This transition between prison and community is identified as a high-risk period for PWID and pivotal to HCV treatment uptake, prevention and elimination [19, 60]. This model involved the linking of prisoners not started on treatment to the specialist hospital service that provides in-reach hepatology services to the IPS. It was hoped that this approach might increase uptake in the community since the specialist nurse was common to both locations and would be known to the patient.

The use of HCV serology markers and current fibroscan scores are strengths of this study. The large numbers screened and followed 12 months later is a further strength of this unique study. There are a number of limitations to this study including it being male only and single site, which reduces its generalisability. A further limitation of this study is that it is observational in design and does not have a comparative arm. Comparing the effectiveness of different active $\mathrm{HCV}$ case-finding models would increase the utility of its findings, but the implementation of such a study design in a large working prison is difficult. Consent to follow up prisoners on release to the community would have benefitted the study's findings. Data on the cost-effectiveness of this model is currently underway and will be published at a later date.

\section{Conclusion}

Large numbers of Irish male prisoners having a history of IDU are frequently incarcerated from a young age and have multiple risk factors for $\mathrm{HCV}$ acquisition. A peersupported screening initiative is both a feasible and an acceptable model of active $\mathrm{HCV}$ case finding in a prison setting. This model identified 50 cases of untreated active HCV infection of which 19 had not been identified at committal. Prison-based hepatology nurse specialist facilitated the linking of 39 active $\mathrm{HCV}$-infected prisoners to $\mathrm{HCV}$ assessment and care. Prisoners can be successfully treated in prison settings, but significant numbers will still require linkage to community $\mathrm{HCV}$ treatment services. Supporting prisoners while transitioning to the community is key to optimising HCV management. There is a 
high concordance between prisoners' self-declared HCV status and serology status at committal. This finding supports the devolvement of $\mathrm{HCV}$ treatment pathways based on self-declared HCV status which could reduce assessment time and linkage to treatment particularly for the large numbers of prisoners who serve short prison sentences. The complexities of prison environments require a planned and coordinated approach to $\mathrm{HCV}$ care to optimise outcomes. Incarceration offers an ideal public health opportunity to engage with and support a high-risk group of $\mathrm{HCV}$-infected PWID with prison and community-based health services.

\begin{abstract}
Abbreviations
+ve: Positive; Ab: Antibody; BBV: Blood-borne virus; DAA: Direct-acting antivirals; DBS: Dried blood spot; ECDC: European Centre for Disease Prevention and Control; EMCDDA: European Centre for Monitoring of Drugs and Drug Addiction; HBV: Hepatitis B virus; HCV: Hepatitis C virus; HIV: Human immunodeficiency virus; IDU: Injecting drug use; IPS: Irish Prison Service; IV: Intravenous; LTFU: Lost to follow-up; MMT: Methadone maintenance treatment; NVRL: National Virus Reference Laboratory; PCR: Polymerase chain reaction; PHMS: Prison Health Management System; POC: Point of care; PWID: People who inject drugs; RNA: Ribonucleic acid; SD: Standard deviation; SPSS: Statistical Package for Social Sciences; SVR: Sustained virological response; -ve: Negative; WHO: World Health Organization
\end{abstract}

\section{Acknowledgements}

The authors would like to acknowledge and thank the staff of the HepCare Europe project and Irish Prison Service who supported and helped with the project. Furthermore, we would like to pay special thanks to the Irish Red Cross Peer Support Network who contributed significantly to the design and implementation of the study. Their manager, Graham Betts-Symonds, is included as a contributing author.

\section{Authors' contributions}

$D C$ is the lead author. Planning was done by DC, WC, MK, TM, SM, SJM, EOC, DOR, GBS, CT, MCVH, and JSL. Implementation was done by DC, RM, MK, TM, SJM, EOC, GBS, and CT. Data collection was done by DC, RM, MK, TM, SJM, EOC, GBS, and CT. Data interpretation and analysis was done by DC, RM, and EL. Drafting of the manuscript was done by DC. The review and finalising of the manuscript was done by DC, RM, WC, MK, EL, TM, SM, SJM, EOC, DOR, GBS, CT, MCVH, and JSL. All authors read and approved the final manuscript.

\section{Funding}

No financial support was received for this study.

\section{Availability of data and materials}

The datasets used and/or analysed during the current study are available from the corresponding author on reasonable request.

\section{Ethics approval and consent to participate}

Ethical approval was obtained from the Mater Ethics Committee as part of the Seek and Treat component of The European Hep Care Project and supported and endorsed by the IPS ethics group. All study participants were given a patient information leaflet and asked to sign a consent form. No inducements were offered.

\section{Consent for publication}

Not applicable.

\section{Competing interests}

The authors declare that they have no competing interests.

\section{Author details}

'Irish College of General Practitioners, Lincoln Place, Dublin 2, Ireland. ${ }^{2}$ School of Medicine, University College Dublin, Dublin, Ireland. ${ }^{3}$ Irish Prison Service, Dublin, Ireland. ${ }^{4}$ Trinity College Dublin, Dublin, Ireland. ${ }^{5}$ Department of Infectious Diseases, Mater Misericordiae University Hospital, Dublin, Ireland. ${ }^{6}$ St. James' Hospital, Dublin, Ireland. 7 Irish Red Cross/Irish Prison Service, Dublin, Ireland. ${ }^{8}$ University of Florida, Gainesville, USA. ${ }^{9}$ Liverpool John Moores University, Liverpool, UK.

Received: 19 March 2019 Accepted: 4 June 2019

Published online: 05 July 2019

\section{References}

1. Vescio MF, Longo B, Babudieri S, Starnini G, Carbonara S, Rezza G, et al. Correlates of hepatitis $C$ virus seropositivity in prison inmates: A metaanalysis. J Epidemiol Community Health. 2008;62:305-13. https://doi.org/10. 1136/jech.2006.051599.

2. Larney S, Kopinski H, Beckwith CG, Zaller ND, Des JD, Hagan H, et al. Incidence and prevalence of hepatitis $\mathrm{C}$ in prisons and other closed settings: results of a systematic review and meta-analysis. Hepatology. 2013; 58:1215-24. https://doi.org/10.1002/hep.26387.

3. Peña-Orellana M, Hernández-Viver A, Caraballo-Correa G, Albizu-García CE. Prevalence of HCV risk behaviors among prison inmates: tattooing and injection drug use. J Health Care Poor Underserved. 2012;22:962-82. https:// doi.org/10.1353/hpu.2011.0084

4. Martin NK, Vickerman P, Dore GJ, Hickman M. The hepatitis C virus epidemics in key populations (including people who inject drugs, prisoners and MSM). Curr Opin HIV AIDS. 2015;10:374-80. https://doi.org/10.1097/coh. 0000000000000179.

5. Bretaña NA, Boelen L, Bull $R$, Teutsch S, White PA, Lloyd AR, et al. Transmission of hepatitis C virus among prisoners, Australia, 2005-2012. Emerg Infect Dis. 2015;21:765-74. https://doi.org/10.3201/eid2105.141832.

6. Fazel S, Baillargeon J. The health of prisoners. Lancet. 2011;377:956-65. https://doi.org/10.1016/S0140-6736(10)61053-7.

7. Arain A, Robaeys G, Stöver H. Hepatitis C in European prisons: a call for an evidence-informed response. BMC Infect Dis. 2014;14:S17. https://doi.org/10 1186/1471-2334-14-S6-S17.

8. World Health Organisation. Prisons and health 2014:207.

9. Rumble C, Pevalin DJ, OMoore É. Routine testing for blood-borne viruses in prisons: a systematic review. Eur J Public Health. 2015;25:1078-88. https:// doi.org/10.1093/eurpub/ckv133.

10. European Centre for Disease Prevention and Control and the European Monitoring Centre for Drugs and Drug Addiction. Systematic review on active case finding of communicable diseases in prison settings. Stockholm. p. 2017. https://doi.org/10.2900/348536.

11. Marco A, Gallego C, Cayla JA. Incidence of hepatitis c infection among prisoners by routine laboratory values during a 20-year period. PLoS One. 2014:9:e90560. https://doi.org/10.1371/journal.pone.0090560.

12. European Association for the Study of the Liver. EASL Recommendations on Treatment of Hepatitis C 2016. J Hepatol. 2017;66:153-94. https://doi.org/10. 1016/j.jhep.2016.09.001.

13. World Health Organisation. Guidelines for the screening care and treatment of persons with chronic hepatitis C infection. Geneva; 2016.

14. Chung RT, Davis GL, Jensen DM, Masur H, Saag MS, Thomas DL, et al. Hepatitis C guidance: AASLD-IDSA recommendations for testing, managing, and treating adults infected with hepatitis C virus. Hepatology. 2015:62:93254. https://doi.org/10.1002/hep.27950

15. Thompson AJV. Australian recommendations for the management of hepatitis C virus infection: a consensus statement. Med J Aust. 2016;204:1-5. e1. https://doi.org/10.5694/mja16.00106

16. Department of Health. Hepatitis C screening (NCEC National Clinical Guideline No. 15). Dublin; 2017

17. Larney S, Beckwith C, Zaller N, Montague B, Rich J. "Seek, test, treat and retain" for hepatitis $C$ in the United States criminal justice system. Int J Prison Health. 2014;10:164-71. https://doi.org/10.1108/IJPH-11-2013-0051.

18. Irish Penal Reform Trust. Facts \& Figures | Irish Penal Reform Trust (IPRT). Dublin; 2018

19. Stone J, Martin NK, Hickman M, Hutchinson SJ, Aspinall E, Taylor A, et al. Modelling the impact of incarceration and prison-based hepatitis $C$ virus $(\mathrm{HCV})$ treatment on $\mathrm{HCV}$ transmission among people who inject drugs in Scotland. Addiction. 2017;112:1302-14. https://doi.org/10.1111/add.13783.

20. Morris MD, Brown B, Allen SA. Universal opt-out screening for hepatitis C virus ( $\mathrm{HCV}$ ) within correctional facilities is an effective intervention to improve public health. Int J Prison Health. 2017;13:192-9. https://doi.org/10. 1108/IJPH-07-2016-0028. 
21. Martin NK, Hickman M, Miners A, Hutchinson SJ, Taylor A, Vickerman P. Cost-effectiveness of HCV case-finding for people who inject drugs via dried blood spot testing in specialist addiction services and prisons. BMJ Open. 2013;3:e003153. https://doi.org/10.1136/bmjopen-2013-003153.

22. Lee SR, Kardos KW, Schiff E, Berne CA, Mounzer K, Banks AT, et al. Evaluation of a new, rapid test for detecting HCV infection, suitable for use with blood or oral fluid. J Virol Methods. 2011;172:27-31. https://doi.org/10.1016/j. jviromet.2010.12.009

23. Kronfli N, Linthwaite B, Kouyoumdjian F, Klein MB, Lebouché B, Sebastiani G, et al. Interventions to increase testing, linkage to care and treatment of hepatitis $\mathrm{C}$ virus ( $\mathrm{HCV}$ ) infection among people in prisons: a systematic review. Int J Drug Policy. 2018;57:95-103. https://doi.org/10.1016/j.drugpo. 2018.04.003.

24. Kuncio DE, Newbern EC, Fernandez-Viña MH, Herdman B, Johnson CC, Viner KM. Comparison of Risk-Based Hepatitis C screening and the true seroprevalence in an urban prison system. J Urban Heal. 2015;92:379-86. https://doi.org/10.1007/s11524-015-9945-4

25. Centre for Disease Prevention E, Kreisel ed U. Public health guidance on active case finding of communicable diseases in prison settings. Prevention and control of communicable diseases in prison settings. Stockholm and Lisbon: 2018. doi:https://doi.org/10.2900/619331.

26. Ross MW, Harzke AJ, Scott DP, McCann K, Kelley M. Outcomes of Project Wall Talk: an HIV/AIDS peer education program implemented within the Texas State prison system. AIDS Educ Prev. 2006;18:504-17. https://doi.org/ 10.1521/aeap.2006.18.6.504.

27. Drummond A, Codd M, Donnelly N, McCausland D, Mehegan J, Daly L, et al. Study on the prevalence of drug use, including intravenous drug use, and blood-borne viruses among the Irish prisoner population. Dublin: National Advisory Committee on Drugs and Alcohol; 2014.

28. Allwright S, Bradley F, Long J, Barry J, Thornton L, Parry JV. Prevalence of antibodies to hepatitis B, hepatitis C, and HIV and risk factors in Irish prisoners: results of a national cross sectional survey. BMJ. 2000;321:78-82. https://doi.org/10.1136/bmj.321.7253.78.

29. Henderson C, Madden A, Kelsall J. 'Beyond the willing \& the waiting' - the role of peer-based approaches in hepatitis C diagnosis \& treatment. Int J Drug Policy. 2017;50:111-5. https://doi.org/10.1016/j.drugpo.2017.08.004.

30. Treloar C, Rance J, Haber P, Bath N, Day C, Dore G, et al. How to build trustworthy hepatitis $C$ services in an opioid treatment clinic? A qualitative study of clients and health workers in a co-located setting. Int J Drug Policy. 2014;25:865-70. https://doi.org/10.1016/j.drugpo.2014.01.011.

31. Bagnall AM, South J, Hulme C, Woodall J, Vinall-Collier K, Raine G, et al. A systematic review of the effectiveness and cost-effectiveness of peer education and peer support in prisons. BMC Public Health. 2015;15:290. https://doi.org/10.1186/s12889-015-1584-x.

32. Macarthur GJ, Sean H, Deborah MC, Matthew H, Rona C. Peer-led interventions to prevent tobacco, alcohol and/or drug use among young people aged 11-21 years: a systematic review and meta-analysis. Addiction. 2016;111:391-407. https://doi.org/10.1111/add.13224.

33. South J, Bagnall A-M, Hulme C, Woodall J, Longo R, Dixey R, et al. A systematic review of the effectiveness and cost-effectiveness of peer-based interventions to maintain and improve offender health in prison settings. Heal Serv Deliv Res. 2014;2:1-218. https://doi.org/10.3310/hsdr02350.

34. Woodall J, South J, Dixey R, De Viggiani N, Penson W. Expert views of peerbased interventions for prisoner health. Int J Prison Health. 2015;11:87-97. https://doi.org/10.1108/IJPH-10-2014-0039.

35. Swan D, Cullen W, Macias J, Oprea C, Story A, Surey J, et al. Hepcare Europe - bridging the gap in the treatment of hepatitis C: study protocol. Expert Rev Gastroenterol Hepatol. 2018;12:303-14. https://doi. org/10.1080/17474124.2018.1424541.

36. Lambert J, Cullen W, Oprea C, Story A, Sanchez J, Surey J. Hepcare Europe: HepCheck; reaching vulnerable populations. J Hepatol. 2018;68:S153.

37. Møller L, Stöver $H$, Jürgens $R$, Gatherer A, Nikogosian $H$. Health in prisons: a WHO guide to the essentials in prison health; 2007.

38. Dolan K, Wirtz AL, Moazen B, Ndeffo-mbah M, Galvani A, Kinner SA, et al. Global burden of HIV, viral hepatitis, and tuberculosis in prisoners and detainees. Lancet. 2016;388:1089-102. https://doi.org/10.1016/S0140-6736(16)30466-4.

39. Post JJ, Dolan KA, Whybin LR, Carter IWJ, Haber PS, Lloyd AR. Acute hepatitis $C$ virus infection in an Australian prison inmate: tattooing as a possible transmission route. Med J Aust. 2001;174:183-4.

40. WHO 2017. Global Hepatitis Report 2017. Geneva: World Health Organization; 2017.
41. Bielen R, Stumo SR, Halford R, Werling K, Reic T, Stöver H, et al. Harm reduction and viral hepatitis C in European prisons: a cross-sectional survey of 25 countries. Harm Reduct J. 2018;15. https:/doi.org/10.1186/s12954-018-0230-1.

42. Platt L, Minozzi S, Reed J, Vickerman P, Hagan $H$, French $C$, et al. Needle syringe programmes and opioid substitution therapy for preventing hepatitis $C$ transmission in people who inject drugs. Cochrane Database Syst Rev. 2017;(2017):CD012021. https://doi.org/10. 1002/14651858.CD012021.pub2.

43. Crowley D, Van Hout MC, Lambert JS, Kelly E, Murphy C, Cullen W. Barriers and facilitators to hepatitis $\mathrm{C}$ (HCV) screening and treatment-a description of prisoners' perspective. Harm Reduct J. 2018;15:62. https://doi.org/10.1186/ s12954-018-0269-z.

44. Khaw FM, Stobbart L, Murtagh MJ. "I just keep thinking I haven't got it because I'm not yellow": a qualitative study of the factors that influence the uptake of hepatitis $C$ testing by prisoners. BMC Public Health. 2007;7:98. https://doi.org/10.1186/1471-2458-7-98.

45. Yap L, Carruthers S, Thompson S, Cheng W, Jones J, Simpson P, et al. A descriptive model of patient readiness, motivators, and hepatitis C treatment uptake among Australian prisoners. PLoS One. 2014;9:e87564. https://doi.org/10.1371/journal.pone.0087564.

46. Arain A, De Sousa J, Corten K, Verrando R, Thijs H, Mathei C, et al. Pilot Study: Combining formal and peer education with fibroscan to increase HCV screening and treatment in persons who use drugs. J Subst Abuse Treat. 2016;67:44-9. https://doi.org/10.1016/j.jsat.2016. 04.001.

47. Harris M, Ward E, Gore C. Finding the undiagnosed: a qualitative exploration of hepatitis C diagnosis delay in the United Kingdom. J Viral Hepat. 2016;23: 479-86. https://doi.org/10.1111/jvh.12513.

48. Rhodes T, Harris M, Martin A. Negotiating access to medical treatment and the making of patient citizenship: the case of hepatitis $C$ treatment. Sociol Heal IIIn. 2013;35:1023-44. https://doi.org/10.1111/1467-9566.12018.

49. Harris M, Rhodes T. Hepatitis C treatment access and uptake for people who inject drugs: a review mapping the role of social factors. Harm Reduct J. 2013;10:7. https://doi.org/10.1186/1477-7517-10-7.

50. Roose RJ, Cockerham-Colas L, Soloway I, Batchelder A, Litwin AH. Reducing barriers to hepatitis $C$ treatment among drug users: an integrated hepatitis C peer education and support program. J Health Care Poor Underserved. 2014;25:652-62. https://doi.org/10.1353/hpu.2014.0096.

51. Lafferty L, Treloar C, Guthrie J, Chambers GM, Butler T. Social capital strategies to enhance hepatitis $C$ treatment awareness and uptake among men in prison. J Viral Hepat. 2017;24:111-6. https://doi.org/10. 1111/jvh.12627.

52. South J, Woodall J, Kinsella K, Bagnall AM. A qualitative synthesis of the positive and negative impacts related to delivery of peer-based health interventions in prison settings. BMC Health Serv Res. 2016;16:525. https:// doi.org/10.1186/s12913-016-1753-3.

53. O'Keefe D, Aitken C, Higgs P, Dietze P. Concordance between self-reported and actual hepatitis $C$ virus infection status in a cohort of people who inject drugs. Drug Alcohol Rev. 2013;32:208-10. https://doi.org/10.1111/j.14653362.2012.00502.x

54. Thornton L, Barry J, Long J, Allwright S, Bradley F, Parry JV. Comparison between self-reported hepatitis B, hepatitis C, and HIV antibody status and oral fluid assay results in Irish prisoners. Commun Dis public Heal. 2000;3: 253-5.

55. Mahowald MK, Larney S, Zaller ND, Scharff N, Taylor LE, Beckwith $C G$, et al. Characterizing the burden of hepatitis $c$ infection among entrants to Pennsylvania state prisons, 2004 to 2012. J Correct Heal Care. 2016;22:41-5. https://doi.org/10.1177/1078345815618384.

56. Aspinall EJ, Mitchell W, Schofield J, Cairns A, Lamond S, Bramley P, et al. A matched comparison study of hepatitis $C$ treatment outcomes in the prison and community setting, and an analysis of the impact of prison release or transfer during therapy. J Viral Hepat. 2016;23:1009-16. https://doi.org/10.1111/jvh.12580.

57. Redman JS, Sterling RK. Treating HCV in a Captive Audience: Eradication Efforts in the prison microenvironment. Am J Gastroenterol. 2018;113:15857. https://doi.org/10.1038/s41395-018-0201-x.

58. Swan D, Long J, Carr O, Flanagan J, Irish H, Keating S, et al. Barriers to and facilitators of Hepatitis $C$ testing, management, and treatment among current and former injecting drug users: a qualitative exploration. AIDS Patient Care STDS. 2010;24:753-62. https://doi.org/10. 1089/apc.2010.0142 
59. Howes N, Lattimore S, Irving WL, Thomson BJ. Clinical care pathways for patients with hepatitis C: reducing critical barriers to effective treatment. Open Forum Infect Dis. 2016;3:ofv218. https://doi.org/10.1093/ofid/ofv218.

60. Merrall ELC, Kariminia A, Binswanger IA, Hobbs MS, Farrell M, Marsden J, et al. Meta-analysis of drug-related deaths soon after release from prison. Addiction. 2010;105:1545-54. https://doi.org/10.1111/j.1360-0443. 2010.02990.x.

\section{Publisher's Note}

Springer Nature remains neutral with regard to jurisdictional claims in published maps and institutional affiliations.

Ready to submit your research? Choose BMC and benefit from:

- fast, convenient online submission

- thorough peer review by experienced researchers in your field

- rapid publication on acceptance

- support for research data, including large and complex data types

- gold Open Access which fosters wider collaboration and increased citations

- maximum visibility for your research: over $100 \mathrm{M}$ website views per year

At $\mathrm{BMC}$, research is always in progress.

Learn more biomedcentral.com/submissions 